\title{
Teachers' Conceptions of Assessment Using Brown's Four-Factor Model and DepEd Assessment Policy: Implications for Policy Review
}

\author{
Joan Deocareza Rural ${ }^{\mathrm{a}}$ \\ ${ }^{a}$ Polytechnic University of the Philippines,Sta. Mesa, Manila
}

Article History: Received: 10 November 2020; Revised 12 January 2021 Accepted: 27 January 2021; Published online: 5 April 2021

\begin{abstract}
The study determined teachers' conceptions on assessment which were bases in developing recommendations for policy review. The study used survey questionnaires adopted from Brown's COA-III and an additional researcher-made questionnaire from DepEd Assessment Policy. The respondents are the 408 mathematics teachers from the different schools of National Capital Region using Cluster Sampling. Teachers "strongly agreed" that assessment held the students and school accountable, it's for the improvement of the teaching and learning process, and they don't believe that assessment is irrelevant. The teachers also believed that a sound assessment must be standards-based, for concept development, formative and summative. Moreover, eight variables are found to be correlated: school accountability, student accountability, improvement, standards-based, concept development, formative and summative. Assessment should be designed from classroom to national levels. Teachers' assessments may consider the factors school accountability, student accountability, improvement, standardsbased, concept development, formative, and summative. Teachers should undergo extensive training concerning classroom assessment. Teachers must see to it that in every assessment they implement in their class, it should always be aligned to the learning objectives whether the assessment is formative or summative for them to be properly informed regarding the learning development and achievement of the students..
\end{abstract}

Keywords: Assessment Policy, Conceptions of Assessment, Policy Review

\section{Introduction}

The various changes brought about by national and global frameworks such as globalization, ASEAN integration, the $\mathrm{K}$ to 12 Reform, and the changing characteristics of the 21 st century learners necessitate the improvement and adaptability of education (PPST, 2018).

Assessment is an essential aspect of the educative process. But it is one of the least understood processes in education (DepEd Order No. 29, S. 2017). As one of the major elements of the curriculum, assessment must be handled and studied delicately, because it mirrors the success of the reform. Since assessment serves a lot of purposes/functions like teaching quality, giving relevant and necessary information about the learning progress of students as well as the accountability of programs and institutions, it is therefore a vital aspect in educational reform (1).

The implementation of K-12 Curriculum, necessitates the accurate assessment of student achievement in all school levels. Teachers' conceptions about assessment must be examined because they strongly influence how teachers design, implement, and interpret (the results of) classroom assessments (2). Apparently, despite this point, Black and Wiliam emphasized that there are research evidences that the daily classroom assessment is afflicted with challenges and shortcomings (3). The connection between teachers' assessment conceptions and practices give necessary indication for the upliftment of assessment in professional development which recognizes the role of classroom assessment in supporting learning and teaching.

It is generally accepted that teachers' conceptions and knowledge about the components of teaching-learning process influence their classroom practices. The knowledge and belief of teachers has a significant function in how they interpret new information and experience, and these interpretations, in turn, guide their instructional practices (4). According to Brown, conceptions are proposed to be organizing frameworks in which individuals will comprehend, react, and interact to a phenomenon (5).

One very important component of the teaching-learning process in education that is guided by teachers' conceptions is classroom assessment. It provides multiple good intentions such as giving information about the students' progress and learning, the quality of teaching, and accountability of program and institution. It is a process used in the classroom routine used by the teachers for them to obtain information about the performance of students on the different assessment tasks, either individually or as a group. By using different assessment 
methods and techniques, finding out the extent the students need to achieve as well as the target instructional outcomes will be easier.

Teachers play a very important role and function in assessment because they have the responsibility of recording and reporting accurate and fair student learning, based on the variety of evidences from different contexts and applications. Levin emphasized that, teachers' belief is understood to be considered part of a complicated multi-dimensional system which may include opposing conceptions that may or may not be observed through trial, depending on the individual or in context (6). The latest view is that, teachers' conceptions are considered key factors, and important predictors of the teaching and learning processes in education.

Most of us probably believed that our belief is different from how we behave. In the field of education, we may also have experienced similar variations or inconsistencies in assessment policies. Policy makers keep on raising standards by planning and implementing reforms systematically, but, they sometimes fail to monitor and assess what teachers really do to accomplish the educational goals. They usually propose what teachers should do in classrooms, but the question is, do they really monitor or even recognize what teachers are doing, what they think about recommended changes, how they interpret those changes, and put them into practice? Considering these questions and trying to find answers are significant steps to be able to attain the goals in the education field.

Teachers conduct their assessment practices influenced by their respective conceptions and purposes on assessment, however, these areas are less explored and studied in the Philippine context. The policy-makers may or may not be empirically informed as to how the teachers conceive assessment. In effect, when the policy-makers in the country design their guidelines for classroom assessment, the prescribed policy guidelines may or may not entirely coincide with the teachers ${ }^{\text {ee }}$ conceptions of assessment which, in turn, dictate the teachers ${ }^{\text {ee }}$ assessment practices and eventually reflect the attainment of the curricular visions and goals. This unexplored gap between theory, policy and practice on assessment give crucial feedback to the policy-makers whether or not the achievement of the 21 st century skills of the students could be realized in the long run.

Thus, this study explored information from mathematics teachers about their conceptions (beliefs) of assessment that strongly influence how teachers plan, design, implement, analyze, and interpret the results of classroom assessments. The result of the research is expected to contribute for comprehensive disposition and understanding the educational assessment of teachers and for the researcher to be able to come up with recommendations for policy review.

\section{Methods}

The research utilized quantitative-descriptive study and a Structural Equation Modeling (SEM) technique to analyze structural relationships. Using cluster sampling, the respondents of the study were the randomly selected junior high school mathematics teachers of secondary public schools in the National Capital Region. The questionnaire used contains the profile of the respondents, assessment conceptions by Brown (COA-III, 2004), and assessment conception based on the Policy Guidelines in Classroom Assessment for K-12 Basic Education Program of the Department of Education (DepEd). The respondents were asked about their assessment conceptions through a five-point scale: (5) Definitely Agree; (4) Strongly Agree; (3) Agree; (2) Strongly Disagree and (1) Definitely Disagree. The COA-III is a self-report attitude inventory that measures teachers' degree of agreement or disagreement with statements related to assessments. The instrument was developed by Brown (2004) within the theoretical framework delineated by the different literature on classroom assessment. The COAIII instrument is very applicable in gathering information for the purpose of policy planning and in assisting for professional development. It can also be an excellent drive in tailoring policy on assessment as well as for the professional development of the teachers in a way that assessment boosts the students' achievement standard and enhances the quality of teachers' teaching. Last part of the questionnaire is about the conceptions of assessment pertaining to DepEd Order No. 8, S. 2015 where the respondents gave their conceptions on the following factor structures: standards-based; concept development; formative; and summative.

Descriptive statistics and SEM were used in the treatment of data. Frequency and percentage distribution were used to be able to determine the profile of the respondents. Weighted mean and standard deviations were computed for the subscales of the COA-III and DepEd assessment policy. Mean is the statistical tool used to determine how the respondents agreed or disagreed on the conceptions of assessment, and to be able to find out how the conceptions of assessment might associate, structural equation modelling (SEM) was utilized

\section{Results and Discussions}

The goal of this study is to come up with recommendations for policy review based on the respondents' conceptions of assessment using Brown's Four-Factor model and DepEd's Assessment Policy. 
The respondents strongly agreed on all statements of school accountability obtaining a grand mean of 3.88. The result implies that junior high school mathematics teachers find school accountability as a strong factor in assessment. The respondents also strongly agreed on all statements of student accountability with a grand mean of 3.83 which shows that the junior high school mathematics teachers also find student accountability as a strong factor in assessment. All statements under improvement - describe, student learning, validity and teaching obtained a grand mean of 3.96, 3.91, 3.57, and 3.59 respectively which were all interpreted as "strongly agree". This means that assessment helps students improve their learning, which must be valid and reliable always and helps teachers improve their teaching.

Table 1

Respondents' Conceptions of Assessment Based on Brown’s Four-Factor Model and DepEd Assessment Policy

\begin{tabular}{|c|c|c|c|}
\hline & FACTOR & $\begin{array}{l}\text { GRAND } \\
\text { MEAN }\end{array}$ & $\begin{array}{c}\text { VERBAL } \\
\text { INTERPRETATION }\end{array}$ \\
\hline \multirow{9}{*}{ 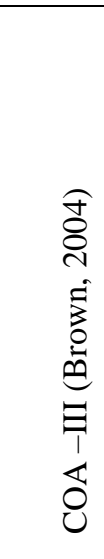 } & School Accountability & 3.88 & Strongly Agree \\
\hline & Student Accountability & 3.83 & Strongly Agree \\
\hline & Improvement - Describe & 3.96 & Strongly Agree \\
\hline & Improvement-Student Learning & 3.91 & Strongly Agree \\
\hline & Improvement - Validity & 3.57 & Strongly Agree \\
\hline & Improvement - Teaching & 3.89 & Strongly Agree \\
\hline & Irrelevance $-\mathrm{Bad}$ & 2.30 & Strongly Disagree \\
\hline & Irrelevance - Ignore & 2.03 & Strongly Disagree \\
\hline & Irrelevance - Accurate & 3.01 & Agree \\
\hline \multirow{4}{*}{ 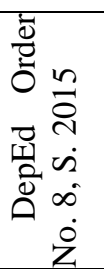 } & Standards - Based & 3.93 & Strongly Agree \\
\hline & Concept Development & 3.64 & Strongly Agree \\
\hline & Formative & 3.85 & Strongly Agree \\
\hline & Summative & 3.94 & Strongly Agree \\
\hline
\end{tabular}

The variables irrelevance-bad and ignore obtained the grand mean of 2.30 and 2.03 respectively which were interpreted as "strongly disagree". The results imply that the respondents did not consider assessment as a bad factor and it should not be ignored. But they agreed that accuracy is also a factor to consider in assessment.

Meanwhile, all the statements from the variables standards-based, concept development, formative and summative got a grand mean of $3.93,3.64,3.85$, and 3.94 respectively which were all interpreted as "strongly agree". The result implies that the respondents agreed strongly that being standards-based is one of the purposes of assessment in K-12 curriculum. Assessment should be according to the content, performance, and learning standards set by the Department of Education. It further shows that in assessment, concept development must also be considered, and the key purposes of assessment are "assessment for, as, and of learning.

The result is similar to the findings of Khan about secondary school mathematics teachers' conception about assessment where it showed a high level of agreement with the factor structure 'school accountability', student accountability', and 'improvement' but in contradiction with the 'irrelevance' conception where the respondents showed a comparatively low level of agreement (7).

Davis and Neitzel found in their study that the teachers are not constantly using formative assessment methods, although this conception that they have partaken in connection to assessment were eminently eloquent and based deeply in the framework of self-regulated learning (8).

In the study of Vandeyar \& Killen, they have demonstrated that the various conceptions on assessment may direct to various assessment practices (9). Therefore, those teachers who considers assessment as a utilizable tool in augmenting the needed information in decision making specifically connected to learning will steadily utilize the tools in assessment the assessment tools that are correlative to the teaching and learning process. The teachers who believed in students' responsibility and accountability will turn to the formal summative assessment methods. 
All of the statements in Brown's (2004) COA-III loaded significantly on the hypothesized factor $(\mathrm{p}<0.005)$ since all p-values are less than 0.005. Thus, the observed variables of the variables school accountability, student accountability, improvement and irrelevance, emerged as factor structures to the conception of assessment.

Moreover, the statements from DepEd assessment policy loaded significantly on the hypothesized factor $(\mathrm{p}<0.005)$ since all $\mathrm{p}$-values are less than 0.0005 . Thus, the observed variables standards-based, concept development, formative and summative, emerged as factor structures to the conception of assessment.

Table 2

Relationships Emerged Among the Eight (8) Variables Using COA-III and DepEd Assessment Policy

\begin{tabular}{|c|c|c|c|}
\hline Variable & ESTIMATE & P-VALUE & REMARK \\
\hline $\begin{array}{l}\text { School Accountability and Student } \\
\text { Accountability }\end{array}$ & 0.880 & 0.000 & Significant \\
\hline School Accountability and Improvement & 0.714 & 0.000 & Significant \\
\hline School Accountability and Irrelevance & 0.086 & 0.387 & Not Significant \\
\hline School Accountability and Standards-Based & 0.717 & 0.000 & Significant \\
\hline $\begin{array}{cccc}\text { School Accountability } & \text { and } & \text { Concept } \\
\text { Development } & & & \end{array}$ & 0.860 & 0.000 & Significant \\
\hline School Accountability and Formative & 0.587 & 0.000 & Significant \\
\hline School Accountability and Summative & 0.658 & 0.000 & Significant \\
\hline Student Accountability and Improvement & 0.674 & 0.000 & Significant \\
\hline Student Accountability and Irrelevance & 0.059 & 0.533 & Not Significant \\
\hline Student Accountability and Standards-Based & 0.644 & 0.000 & Significant \\
\hline $\begin{array}{cccc}\text { Student } & \text { Accountability } & \text { and } & \text { Concept } \\
\text { Development } & & & \end{array}$ & 0.771 & 0.000 & Significant \\
\hline Student Accountability and Formative & 0.525 & 0.000 & Significant \\
\hline Student Accountability and Summative & 0.600 & 0.000 & Significant \\
\hline Improvement and Irrelevance & 0.109 & 0.360 & Not Significant \\
\hline Improvement and Standards-Based & 0.914 & 0.000 & Significant \\
\hline Improvement and Concept Development & 1.074 & 0.000 & Significant \\
\hline Improvement and Formative & 0.758 & 0.000 & Significant \\
\hline Improvement and Summative & 0.876 & 0.000 & Significant \\
\hline Irrelevance and Standards-Based & 0.034 & 0.724 & Not Significant \\
\hline Irrelevance and Concept Development & 0.212 & 0.004 & Significant \\
\hline Irrelevance and Formative & 0.041 & 0.689 & Not Significant \\
\hline Irrelevance and Summative & 0.087 & 0.364 & Not Significant \\
\hline Standards-Based and Concept Development & 0.773 & 0.000 & Significant \\
\hline Standards-Based and Formative & 0.513 & 0.000 & Significant \\
\hline Standards-Based and Summative & 0.694 & 0.000 & Significant \\
\hline Concept Development and Formative & 0.422 & 0.000 & Significant \\
\hline Concept Development and Summative & 0.403 & 0.000 & Significant \\
\hline Formative and Summative & 0.766 & 0.000 & Significant \\
\hline
\end{tabular}


The $1^{\text {st }}$-order factors school accountability, student accountability, standards-based, concept development, formative and summative are significantly connected to their observed variables. The $1^{\text {st }}$-order factor improvement is also associated with its $2^{\text {nd }}$ order-factors describe, student learning, teaching and validity which are all connected to the observed variables.

All relationships are significant (with p-value of 0.000 less than 0.005 ) except when the factor structure irrelevance is correlated with six other factor structures, school accountability, student accountability, improvement, standards-based, formative and summative with p-values of $0.387,0.533,0.360,0.724,0.689$ and 0.364 respectively which are all greater than 0.005 . Thus, the factor structure irrelevance is not significantly related to the school accountability, student accountability, improvement, standards-based, formative and summative. It is only correlated with the factor concept development with a p-value 0.004 which is less than 0.005 level of significance.

\section{Recommendations for Policy Review}

An assessment policy that is very well planned can inspire learners in a variety of ways. It can also encourage teachers for more effective instruction. Likewise, it can also impart a vision for the students, teachers as well as the school to perform well in their functions and responsibilities. A sound assessment policy makes it sure that not only the policies but the practices as well can upgrade and advance remarkable standards of education for all learners.

Based on the conceptions of assessment of mathematics teachers, the following recommendations for policy review are hereby proposed:

Recommendation 1: Assessment designs should be from classroom to national levels, for the promotion of student understanding through scientific inquiry.

The policy makers may consider school accountability as one of the purposes of assessment by providing information on how well schools are doing, by measuring the worth or quality of schools, by showing the value that the schools added to the learning of students and by keeping schools honest and up-to-scratch. Assessment should also be not just for the improvement of students but for the teachers as well.

Recommendation 2: A pre-service training for teachers about assessment before the opening of the school year should always be conducted for them to become fully aware on how to do/implement the policy guidelines on classroom assessment.

The trainings that may be conducted should be correlated with the real/actual classroom experiences of the teachers in giving assessment and on how they interpret the improvement of students' competence.

It is not enough for teachers to have training only. A follow-up must be conducted in the middle of the school year in order to assess how the teachers are in the implementation process. There are lots of questions and problems that are expected to arise because in the pre-service training, their knowledge is more on the theoretical aspect. In the follow-up, their knowledge is now integrated with issues and challenges in the implementation. Teachers need to know that they are not left alone in the field and that their questions should be addressed. Finally, an evaluation must also be done if there is an attainment of the curricular goals.

Recommendation 3: It is suggested that one purpose of assessment maybe is to determine the effectiveness of the strategy used or the assessment method used.

This study found out that the policy guidelines can be accounted to the conceptions that assessment indicates the effectiveness of one's teaching and use of assessment method.

It is also very important to remember that assessment in classroom serve the purpose of promotion of student learning. Although it may have implications to teaching, assessment must not be an index of effectiveness to their teaching; rather, a tool to improve their teaching practices oriented for the promotion of student learning. Assessment must not also focus on the determination whether such method or strategy is effective or not. Its main focus should be the learning of the students with their experience on that particular assessment procedure. Failure of learning achievement does not necessarily mean failure of the method and it does not necessarily mean also failure of themselves as a teacher employing such method. Hence, the policy makers must use its influence to improve this conception so as not to inflict further external pressure on the teacher and subsequently refine their assessment conceptions and practices.

Recommendation 4: Both teachers and policy makers have to remember that assessment is appropriate if it is guided with a particular purpose, whether it may be for learning, as learning, or of learning. 
This purpose will eventually guide the teacher to implement appropriate assessment methods according to what is required in the competency.

Recommendation 5: The classroom assessment developers should regard sound assessment tools for the teachers for them to execute globally competitive and excellent standards of instructional and assessment practices which are aligned with the current trends and understanding on how students learn and also how to measure, assess, and evaluate their learning.

The assessments given to the learners, as well as the instructional materials of the teachers should give an interpretation of the research findings in a variety of ways that are beneficial for the teaching-learning process. The assessment developers are likewise encouraged to utilize technology in assessing the students' learning.

Recommendation 6: A broad range of competencies and wide forms of student understanding may be covered by large-scale assessment that this research shows are important aspects of student learning.

The different assessment approaches should be utilized to cover the depth and breadth of competencies which are the learning goals of learning in a cognitive domain of the curriculum. To be able to share the students, teachers, and other stakeholders a bright and clear teaching and learning goals as well as excellent performances towards high competence, there's a need to create a large-scale assessment tools and supporting instructional materials. There should be a clear specification of what knowledge and skills are to be assessed as well as the different criteria in assessing/judging the desired outcomes and these should be always available to all students and other concerned individuals. The assessment developers may also try other methods on how to report the results of assessment. These methods should impart valuable differences in performance at different stages of competence in ways that are visible to various stakeholders. There's a meaningful role to play for large-scale assessments in giving reliable data and information for the purpose of decision making for the teachers, parents, school administrators and educational policy makers. These assessments can also communicate significant information on the different kinds of learning the society valued.

Recommendation 7: Clear and specific instruction on how the students learn and how this learning is assessed should be an important component of preservice teaching and professional development programs.

For this to happen, the national standards for teacher licensure and accreditation of programs should consider to include specific requirements that is focused on the integration of learning and assessment in the educational experience of teachers.

A training for teachers in comprehending how the children are learning the subject matter is needed. The teachers also need training on how to utilize the assessment tools and practices to be able for them to gain necessary information about the competence of the students. Likewise, these learning opportunities will be able the teachers to convert their practices in ways that will result not only for the students' benefit but also for theirs. There's also a need for the teachers to gain knowledge in using tools that will result to sound conclusions about student thinking and understanding, and also ways of interpreting the data from assessments.

Moreover, the school administrators should give teachers enough opportunities to just continue learning assessment throughout their entire professional practice. As part of the Philippine Professional Standard for Teachers, professional development is considered vital in improving practice not only for beginning but also for highly competent teachers.

Recommendation 8: Policy makers are encouraged to develop new systems of multiple assessments that would help improve their capability in decision-making about education programs.

National Achievement Test score should not be the only basis in making relevant decisions. Instead, the policy makers may exert more effort in developing new systems of assessment that utilize varied tools in measuring students' performance. They should elevate these new systems of assessment that measure the growth and improvement of students as well as the education system.

Recommendation 9: Policy should also give focus on external assessment and not only on formative assessment in the classroom created to guide learning of students.

The current policy assessment is giving more emphasis on classroom formative assessment and is using it for a variety of purposes. Classroom assessments and large-scale assessments often impart disagreeing goals for learning. These two assessments within a well-founded system should raise from a shared knowledge on how students think and learn in a curriculum domain. 


\section{References}

Opre D. (2015). Teachers' Belief and Educational Research: Cleaning up a Messy Construct. Review of Educational Research, 62 (3), 307-322.

Ballada C. J. A. \& Alino, M. A. C. (2018). Exploring Filipino Teachers' Conceptions of Assessment. Educational Measurement and Evaluation Review (2018), Vol. 9Issue 1@ 2018Philippine Educational Measurement and Evaluation Association

Black, P., \& William, D. (2005). Lessons from Around the World: How Policies, Politics and Cultures Constrain and Afford Assessment Practices. The Curriculum Journal.

Phipps, S., \& Borg, S. (2009). Exploring Tensions Between Teachers' Grammar Teaching Beliefs and Practices. System, 37, 380-390.

Brown, G. T. L. (2004). Teachers' Conceptions of Assessment: Implications for Policy and Professional Development. Assessment in Education: Principles, Policy and Practice, 11, 301-318.

Levin, B. B. (2015). Development of Teachers' Beliefs. In H. Fives \& M. G. Gill (Ed.), International Handbook of Research on Teachers' Beliefs (pp. 48-66). Routledge Taylor \&Francis Group: New York and London.

Khan, A. (2011). Secondary School Mathematics Teachers Conceptions Regarding Assessment (Unpublished master's dissertation). Aga Khan University, Karachi, Pakistan.

Davis, D. S., \& Neitzel, C. (2011). A Self-Regulated Learning Perspective on Middle Grades Classroom Assessment. Journal of Educational Research, 104, 202-215. doi:10.1080/00220671003690148.

Vandeyar, S \& Killen, R., (2007). 'Educators' Conceptions of Classroom Assessment in post-apartheid South Africa', South African Journal of Education, vol. 27, no. 1, pp. 101-115 